\title{
On the Informatization Construction of Grass-roots Statistics under the New Situation
}

\author{
Delun Zhang \\ Yifengdian Town Government, Jimo District, Qingdao 266233, Shandong, China \\ Email: 1916973636@qq.com
}

\begin{abstract}
With the reform, innovation and development of the social economy, a new economic era with high growth has arrived. The upgrading of the information industry is also accelerating, which not only promotes the optimal allocation of resources, but also accelerates the process of economic globalization. This has brought more and more extensive and profound influences to the development of politics, economy, technology, culture, and ideology under the new situation. While the information industry is developing vigorously, we must also recognize the shortcomings in the construction of grassroots statistical information. Especially in the new situation where economic reforms continue to deepen, we must realize the importance of strengthening the informatization construction of grass-roots statistics. It is necessary to speed up the informatization construction and use the advantages of informatization to continuously improve the efficiency of grass-roots statistical work and improve the level of grass-roots services. This article mainly discusses the informatization construction of grass-roots statistics under the new situation, and aims to further promote the informatization construction of grass-roots statistics.
\end{abstract}

Keywords: new situation, grass-roots statistics, informatization construction

\section{Requirements for grass-roots statistical work under the new situation}

With the support of information technology and the creation of a new economy centered on innovation, the era of big data has truly arrived. The construction of the information industry has not only changed people's production and life, but also changed the operating status of various industries. In this context, new requirements have also been put forward for basic-level statistical work.

\subsection{Requirements from the general public and society}

The continuous development of information construction has led to the development of Internet technology. This makes people need high-quality informatized statistical data when dealing with increasingly complex social and economic affairs. Therefore, the basic statistical work needs to strengthen statistical information.

\subsection{Requirements from the grass-roots government statistics department}

Nowadays, with the emergence of the new economy, the social structure is diversified and the economic model is also changing. The era of big data has arrived, and statistical data is growing rapidly. There are more and more types of statistical reports; the situation is becoming more and more complicated; the difficulty of statistical work is becoming more and more difficult. Statistics and informatization have a natural connection, and statistical modernization is inseparable from statistical informatization. Statistical informatization is conducive to improving statistical capabilities, statistical data quality, and government statistical credibility. Therefore, in order to optimize the work process and improve work efficiency, statistical data work should be more accurate, safe and timely. Making full use of modern information technology to fully realize statistical informatization is not only an important content that cannot be replaced by statistical modernization, but also the only way.

\subsection{Statistics requirements from other departments of governments at all levels}

Government departments include a large amount of information from all walks of life in social, economic, cultural and other fields. In the era of big data, various government departments hope to share various statistical data through modern information technology to further meet the needs of industry management. At the same time, these statistics are also the basis for decision-making and macro-control of governments at all levels. This requires strengthening the informatization construction of grass-roots statistics to meet the needs of various government departments for statistical data. 


\section{Importance and necessity of the informatization construction of statistics under the new situation}

\subsection{Strengthening the informatization construction of statistics is an inherent requirement to conform to the development trend of the times}

With the rapid development of Internet technology, information technology has become an important foundation for work in all walks of life. It not only affects all aspects of our production, life, work and study, but also affects the development of the national economy. In this context, in order to conform to the development trend of the times, it is necessary to strengthen the informatization construction of statistics. This is the requirement of the development of the times, the requirement of statistical development, and the requirement of the transformation of government functions under the new situation. National leaders once pointed out that "we must further increase investment and accelerate the informatization construction of statistics from the height of improving the country's basic capabilities and soft power." This shows that under the new situation, the construction of statistical information is the general trend. Therefore, we must advance with the times and forge ahead.

\subsection{Strengthening the informatization construction of statistics is conducive to the improvement of government functions \\ With the continuous deepening and development of reform and opening up in countries around the world, the functions of the government need to be continuously improved to promote the government to have service functions. Strengthening the informatization construction of statistics can improve the information technology capabilities of statistical departments at all levels, prompt information technicians to continuously improve their technical level, further improve statistical work efficiency, and change work styles. Thus, government functions can be perfected in a true sense.}

\subsection{Strengthening the informatization construction of statistics is conducive to improving the overall development level of statistics}

To strengthen the informatization construction of statistics, we must first establish and improve an advanced informatization system level by level to achieve statistical interconnection at all levels. Currently, China has carried out the seventh census. Through the use of information technology and big data for analysis and comparison, the national ID card information, births and deaths and other data are collected to form a national data information platform. This approach improves the efficiency of the census and the quality of the census data. Therefore, strengthening the informatization construction of statistics can improve the level of informatization, ensure the comprehensiveness and effectiveness of information, give full play to the functional advantages of statistical departments, and improve the overall level of statistical undertakings.

\section{The shortcomings of the informatization construction of statistics under the new situation}

\subsection{Some statisticians have insufficient understanding of the informatization construction of statistics}

Judging from the current status of statistical informatization construction, there are some statisticians who are not very motivated in basic statistical work and lack attention to the construction of statistical informatization. Most of them think that information statistics is a systematic project., But in grassroots work, the level of technical operation used does not need to be too high. And statistical information construction is of little importance to them. Under the influence of this kind of thinking, the statisticians are not very motivated and enthusiastic, and only meet the requirements of computers, printers, and simple data analysis in the work process, let alone the improvement of their own technical operation level. Over time, this will increase the difficulty of the construction of basic-level statistical information.

\subsection{The level of the informatization construction of grass-roots statistics varies}

In the process of promoting the construction of statistical informatization, all regions and departments have their own practices and standards. In addition, various local government departments have different levels of support for informatization construction, resulting in an uneven degree of informatization construction in various regions. 


\subsection{Lack of advanced informatization construction equipment and insufficient capital investment}

The support of equipment hardware is an important aspect of promoting the informatization construction of grassroots statistics. In the process of the informatization construction of grass-roots statistics, the most important thing is to have a higher level of hardware equipment. However, in the vast grass-roots areas, due to insufficient local government funding and insufficient attention, the number of hardware equipment required for statistical work is small, and the technology is backward, and it is difficult to introduce advanced operating technology. This has seriously affected the process of the informatization construction of grass-roots statistics.

\subsection{Lack of professional talents for the informatization construction of grass-roots statistics}

High-level and high-quality professionals are inseparable from the informatization construction of grass-roots statistics. However, in the current statistics departments at the basic level, the introduction of professional talents is relatively small, the turnover rate of talents is relatively high, and the high-quality talents who master information technology are relatively scarce. Without a solid talent team, it is difficult to ensure the smooth development of the informatization construction of grass-roots statistics.

\section{Measures to strengthen the informatization construction of grass-roots statistics under the new situation}

\subsection{Improve statisticians' awareness of the informatization construction of grass-roots statistics}

If statisticians are to increase their awareness of informatization construction, they must first enhance their ideological advancement and give full play to the Internet. It is necessary to intensify the propaganda of the informatization construction of statistics, focusing on the importance and necessity of strengthening the informatization construction of grass-roots statistics, so that everyone can attach great importance to this. Secondly, in actual business, we should encourage everyone to strengthen their own operation practice. It is necessary to promote knowledge of statistical information technology through familiar new media methods and easy-to-understand languages to improve everyone's business capabilities. The change in ideological understanding can further promote the improvement of technical operation level, thereby improving the level of grass-roots statistical work.

\subsection{Upgrade hardware equipment and increase capital and technology investment}

Statistical work is not a single collection and summary, it involves multi-department, multi-level information statistics. Therefore, it is very necessary to strengthen the upgrade of hardware equipment. Good hardware equipment is of great benefit to grass-roots statistical work. Through the top-level design, the main statistical information can be collected to the maximum. In the subsequent data retrieval, the statistical agency can obtain different data information in a timely and accurate manner, as well as perform data analysis. The upgrade of hardware equipment requires financial and technical support. Therefore, in order to do a good job in the informatization construction of grass-roots statistics, it is also necessary to prepare an information statistics budget in order to apply for financial appropriations. At the same time, strengthen the skill training of grass-roots statisticians and update equipment to improve work efficiency.

\subsection{Strengthen the construction of the talent teamof grass-roots statistical informatization}

The participation of outstanding talents is an important foundation for the informatization construction of grass-roots statistics. For the construction of an excellent talent team, first of all, it is necessary to create an environment for cultivating informatization talents in the work, and actively carry out various trainings to improve the informatization level of grassroots statisticians. Secondly, it is necessary to attract and retain talents, and expand the information technology talent team through talent development plans or talent introduction plans. Finally, appropriately increase remuneration packages to improve the sense of accomplishment of professionals. Build and train the information technology talent team in many aspects, so as to improve the level of the informatization construction of grass-roots statistics.

\section{Conclusion}

All in all, it is a systematic and complex project to strengthen the informatization construction of grass-roots statistics under the new situation. Therefore, relevant departments must recognize the importance of the informatization construction of grass-roots statistics, change their thinking and concepts, and cultivate excellent information statistics talents. It is necessary to establish a professional technical team who is proficient in statistical business, understands information technology, and knows how to manage, and systematically analyze the deep integration of information technology with 
social public affairs, economic and cultural undertakings. Only in this way can the statistics department be promoted under the new situation, and the informatization construction of grass-roots statistics can be maintained healthy, efficient and continuous.

\section{References}

[1] Wang Shasha. On how to improve the quality of basic statistical work in the information age. Finance and Economics (Academic Edition). 2018; 9(04): 524-525.

[2] Gou Jinpeng. How to improve the quality of basic-level statistical work in the information age. Enterprise Reform and Management. 2018; 6(20): 634-635.

[3] Zheng Xuyi. Discussion on the construction of basic-level statistical information under the background of reform. Modern Business and Trade Industry. 2019; 8(27): 721-722.

[4] Liu Wenning. Thoughts on the Information Construction of Basic Statistics Work. Shandong Industrial Technology. 2019; 12(10): 601-602.

[5] Wu Shude. Discussion on the construction of basic-level statistical information under the new situation. Administrative business assets and finance. 2020;2(10): 397-398.

[6] Ge Shurong. Thoughts on the construction of statistical information in the big data environment. Modern Economic Information. 2019; 12(01): 677-678.

[7] Shao Yan. Some experience in the construction of statistical information. Statistics and Consulting. 2019; 6(02): 909910. 